\title{
A Qualitative Case Study Identifying Metrics for ITIL Request Fulfillment Process: Perspectives of an Information Technology Service Provider Group
}

\author{
Sohel M. Imroz \\ Embry-Riddle Aeronautical University
}

Without metrics, the quality and effectiveness of the IT services cannot be measured or managed. This study examined the request fulfillment process of an IT service provider group, identified that group's perceptions of the most important metrics of the process, and created dashboards to display those metrics. Results found 12 metrics perceived by the group as most important. Three dashboard pages were created using iDashboards. This study should be meaningful to a growing number of IT practitioners because it addressed metrics, measurements, and evaluation of IT processes on which very little previous empirical work has been conducted.

Keywords: Metrics, ITSM, ITIL, Request Fulfillment Process

\section{INTRODUCTION}

Information Technology Service Management (ITSM) refers to "the management of IT services through the use and coordination of people, workflows, and information technology" (Hoerbst, Hackl, Blomer, \& Ammenwerth, 2011, p. 2). ITIL, formerly known as the Information Technology Infrastructure Library, is based on a set of best ITSM practices and provides a framework for managing end-to-end IT services (Kumbakara, 2008). As of February 2019, ITIL 4 is the latest version of the ITIL framework and comprises 34 management practices grouped into three categories (General, Service, and Technical) (Axelos, 2019). Service Request Management practice, commonly known as the Request Fulfillment process, "deals with service requests, defining the roles and activities needed to deliver services" (Mendes \& Mira da Silva, 2011, p. 113).

Recently an increasing number of organizations are shifting their focus on IT to "run like a business" or "act like a business" (Steinberg, 2013, p. 1). IT managers and senior executives of today's organizations (especially the CEO, CFO, and CIOs) consider the evolution of IT from being run as a cost center to an aligned business partner not as a choice, but as an obligation and as a matter of survival (Heller, 2013). This evolution has compelled IT managers and senior executives to measure and evaluate the quality and effectiveness of the services they support (Steinberg, 2013). Without the metrics of ITIL processes supporting a service, the quality and effectiveness of the service cannot be measured or managed. The metrics of ITIL processes must be calculated correctly, and the metrics should be easily accessible and presented in real time (Steinberg, 2013). A dashboard is a user interface that organizes and presents metrics and information that is easy to read, easy to access, and enables managers and decision 
makers to quickly "spot deficiencies without wading through lots of reporting detail" (Steinberg, 2013, p. 25).

Despite the obvious necessity and value of having metrics to measure and manage various ITSM processes, it is surprising that few IT professionals have specific ideas regarding the metrics-what should be measured, how to identify what really matters, or how an ITSM metrics program should be implemented and run (Steinberg, 2013). According to Steinberg (2013), fewer than 5\% of the business organizations measure their IT processes and services "well", about $50 \%$ of the organizations have "some" measures, and fewer than $25 \%$ of the organizations have "absolutely no measures at all" (p. 2). Identifying the most important metrics that really matter and to present them real-time in an easily understandable manner are the first steps for today's IT managers and senior executives in solving a business problem, justifying ITSM initiatives to stakeholders, and making effective management decisions (Steinberg, 2013).

\section{PURPOSE OF THE STUDY}

While metrics have long been a topic of interest, concern, and debate, many organizations still struggle with metrics because they are not entirely sure what should be measured and why, they have too many metrics as opposed to a few that really matter, and they commonly view metrics as an output rather than as an input into business conversations about services or improvement activity (Mann, 2011). Implementing and adopting a new metric can also be challenging because sometimes it causes culture change, frustration, and even resistance (Spafford, 2009). In addition, it is far too common for departments and organizations to set a metric only to later discover that the process and tools in place cannot generate the supporting data (Spafford, 2009). Last, to better manage a process and measure its performance, all metrics pertaining to the process must be clearly understood, well-defined, and achievable so its success can be benchmarked (Spafford, 2009).

However, coming up with a list of clearly understood and well-defined metrics, understanding what data are needed and how to collect them, and securing senior management support in buying necessary tools to present the metrics can hinder understanding, identifying, designing, and developing metrics (Mann, 2011). A review of recent ITSM- and ITIL-related scholarly works pointed to a paucity of research on metrics, measurements, and evaluation of ITIL processes-especially how to identify and develop metrics for ITIL processes (Iden \& Eikebrokk, 2013). This study used a qualitative case study method to address these topics on which little previous empirical work has been conducted. This study examined the request fulfillment process for an information technology service provider group to identify the perceived most important metrics of the process, and to subsequently create dashboards to display those metrics. Primary research questions for this study were:

Research Question 1: What do the group members perceive as being the most important metrics of the ITIL request fulfillment process? This research question was guided by the following sub-questions: How do the group members understand the motives or driving forces behind the process implementation (implementation motives)? What do the group members say about the activities that received constant and careful attention from management during implementation (critical success factors or CSFs)? How do the group members describe the benefits perceived and challenges faced during implementation (benefits and challenges)? What do the group members say about measuring and evaluating over time to understand how well the process is working (metrics, measurements, and key performance indicators)?

Research Question 2: How to create dashboards with the metrics perceived as most important by the group members? This research question was guided by the following sub-questions: What is the process of pulling the data from the source(s) of the metrics? How should the metrics be presented in a dashboard? How to make these dashboards accessible in real time to all group members, managers, stakeholders, and other decision makers? 


\section{LITERATURE REVIEW}

This section provides a review of existing research and literature related to IT Service Management (ITSM) and ITIL. The literature review encompasses three primary goals - first, to summarize, critically analyze, and evaluate previous research available on ITSM and ITIL; second, to identify themes and research contributions to ITSM and ITIL that have emerged from past research; and third, to identify knowledge gaps that can be addressed by the present study. The literature search process used in this study, criteria for inclusion and exclusion of relevant literature, and types of data extracted from each study are briefly described next.

ITIL was developed in 1989 by the Central Computer and Telecommunications Agency (CCTA) in the United Kingdom to help improve IT Service Management in the UK central government (Anderson, 2009). The literature review for the present study started with ITIL Core Publications, comprised of five books on the ITIL lifecycle-Service Strategy, Service Design, Service Transition, Service Operation, and Continual Service Improvement. These five books are the bedrock of the ITIL V3 framework. They provide guidance on the planning, delivery, and management of IT services to support business needs and maximize IT resources and capabilities to drive business value (ITILNews, 2016). ITIL core publications are based on the best practices, principles, and international standards related to IT Service Management and drawn from the public and private sectors worldwide (Office of Government Commerce, 2011). Among all core publications, only the Service Operation book falls within the scope of this literature review, because the request fulfillment process is a part of Service Operation. For this literature review, two versions of ITIL were considered relevant-ITIL V2 (released in 2001) and ITIL V3 (released in 2007). It was appropriate to consider ITIL V2 because it is still widely practiced in many companies worldwide (Gacenga, Cater-Steel, \& Toleman, 2010).

After reviewing ITIL core publications, the literature review then targeted other books published on various ITSM and ITIL topics and peer-reviewed literature on implementation of ITSM and ITIL published between January 1, 2000 and December 31, 2018. The keywords used to select relevant literature were "IT Service Management", "Information Technology Infrastructure Library", and their respective abbreviations, "ITSM" and "ITIL." The main sources of literature included academic and professional journals, international Information Systems conferences, and online research directories and databases. Seventeen journals, proceedings from eight conferences, and six online databases were used in this literature review. The selected journals, conferences, and databases are listed in Table 1 (See Table 1). Articles published only in English were considered in this literature review. Non-research articles and white papers (non-peer reviewed) that are purely descriptive were not considered. 
TABLE 1

JOURNALS, CONFERENCES, AND DATABASES USED

\begin{tabular}{ll} 
Type of Source & Source Name \\
\hline Journals & BMC Medical Informatics and Decision Making \\
& Business \& Information Systems Engineering \\
& Campus-Wide Information Systems \\
& Electronic Journal Information Systems Evaluation \\
& Information \& Management \\
& Information Management and Computer Security \\
& Information Systems E-Business Management \\
& Information Systems Management \\
& Information Technology and Management Science \\
& International Journal of Future Computer and Communication \\
& International Journal of Information and Electronics Engineering \\
& Journal of Computer Information Systems \\
& Journal of Global Information Technology Management \\
& Journal of Service Science and Management \\
& Journal of Software Engineering research and Development \\
& Technology and Investment \\
& Wirtschafts Informatik \\
& Americas Conference on Information Systems (AMCIS) \\
European Conference on Information Systems (ECIS) \\
Hawaii International Conference on System Sciences (HICSS) \\
International Conference on Information Resources Management (CONF- \\
IRM) \\
International Conference of Information Systems (ICIS) \\
International Workshop on Database and Expert Systems Applications \\
Pacific Asia Conference on Information Systems (PACIS) \\
Sprouts \\
Business Source Premier \\
Emerald Insight \\
Web of Science \\
Google Scholar \\
IEEE Xplore \\
Conferences
\end{tabular}

Guided by the sub-questions for Research Question 1, the literature review included articles on the following subtopics: motives, justifications, and benefits of implementing ITSM and ITIL; challenges, barriers, and risks associated with ITSM and ITIL; critical success factors (CSFs), and metrics, measurements, and key performance indicators (KPIs). The following tables (See Table 2, 3, 4, and 5) provide a summary of the literature review findings for this study. 


\section{TABLE 2 \\ MOTIVATIONS, JUSTIFICATIONS, AND BENEFITS OF IMPLEMENTING ITSM AND ITIL PROCESSES}

\begin{tabular}{|c|c|}
\hline Research Studies & Findings \\
\hline Disterer (2012) & $\begin{array}{l}\text { Customer orientation and satisfaction; competitive advantage; trust and reputation; } \\
\text { efficiency, uniformity, transparency, reliability, and continuous improvement of IT } \\
\text { procedures and services; process-orientation; clarity of tasks, roles, and responsibilities; } \\
\text { staff awareness; and reduction of errors, incidents, and derivations. }\end{array}$ \\
\hline
\end{tabular}

Gacenga, Cater-Steel, Improved customer satisfaction; increased availability of services and applications; easier Tan, and Toleman (2011) scheduling of changes; increased first-call resolution rate; more efficient ways of recording, prioritizing, and tracking incidents; standardization of workflows and reporting on SLAs; reduced rework occasions and fewer incidents due to failed changes.

Hoerbst, Hackl, Improve IT services, increase productivity, reduce IT costs.

Blomer, and

Ammenwerth (2011)

Marrone and Kolbe (2011)

Office of

Government

Commerce (2011)

Lapao (2011)

Espindola, Luciano, and Audy (2009)

Pollard and CaterSteel (2009)

Wan and Chan (2008)

Kumbakara (2007)

Cater-Steel, Tan, and Toleman (2006)

Hochstein, Tamm, and Brenner (2005, May)
Improvement in service quality, customer satisfaction, business-IT alignment, call fix rate, and return on investments; reduction in IT downtime and outages; and increased adherence to best practices and standardized processes.

1. Ability to manage various standard services quickly and effectively, increase productivity, and improve quality of the business services and products.

2. Reduce the cost of providing business services by reducing the bureaucracy involved in requesting new services or receiving existing ones.

3. Increase the level of control over requested services through a centralized fulfillment function.

Improvement of IT management; efficiency at point of care, and productivity; and reduction of work disruption costs.

Improved alignment among IT actions and organizational goals and a superior decisionmaking process.

Achieve a more predictable infrastructure due to improved rigor during system changes; improved clarity in roles and responsibilities; reduction in system and service outages; improved coordination between functional teams; seamless end-to-end service; more documented and consistent ITSM processes across the organization; consistent logging of incidents; enhanced productivity; reduced costs; and improved customer satisfaction.

Avoid chaos in operations management and achieve a systematic process; improvement of service target and identification of the most-requested users and services.

Increased IT predictability, efficiency, and service quality; reduced support costs; compliance with regulatory requirements; and better management of end-to-end IT services

Compliance with legal requirements; risk management; cost reduction; and customer satisfaction

Increased client-service orientation and improved quality of IT services; better efficiency due to process standardization, optimization, and automation; and improved transparency and comparability through process documentation and monitoring 


\section{TABLE 3 \\ CHALLENGES, BARRIERS, AND RISKS ASSOCIATED WITH ITSM AND ITIL IMPLEMENTATION}

\begin{tabular}{l}
\hline Research Studies \\
\hline Lapao (2011) \\
Marrone and Kolbe (2011) \\
$\begin{array}{l}\text { Office of Government Commerce } \\
\text { (2011) }\end{array}$
\end{tabular}

Findings

Inadequate readiness for change; knowledge and skill gaps; poorly defined roles and responsibilities; and lack of stakeholder analysis.

Lack of executive support and understanding of ITIL objectives; inadequate knowledge, skills, and funding; and organizational and cultural resistance to change.

Challenges: Clearly defining and documenting the requests handled within the request fulfillment process; establishing self-help front-end capabilities allowing users to easily interact with the process; establishing service-level targets for each type of request; and agreeing on the costs of fulfilling requests.

Risks: Poorly defined scope; poorly designed user interfaces; inability to deal with large number of service requests; and inadequate monitoring capability in gathering accurate metric numbers.

Porter and Cater-Steel (2009)

Staff members performing multiple roles or tasks; changing the corporate culture; difficulty in gaining support from technical staff; difficulties in measuring benefits and return on investments.

Winniford, Conger, and EricksonHarris (2009)

Needs for more information about the framework; difficulty and high costs of implementation; lack of support from senior management and lack of collaboration and participation from business units; inadequate resources and capabilities; tendency to avoid accountability; and outsourcing of IT.

Cater-Steel and McBride (2007)

Persuading individuals' behavior and practices conforming to ITIL best practices; resistance in accepting new processes and procedures; and lack of understanding of why changes are necessary by implementing ITIL.

Cater-Steel, Tan, and Toleman (2006)

Burden on employees; increased levels of stress; loss of morale and productivity; and resistance to change

Hochstein et al. (2005)

Additional costs related to project planning, marketing, and coordination; system development and tool customization; contracting and training of personnel; quality control and consultation; process execution; performance measurement; and cost of running additional infrastructures 
TABLE 4

ITSM AND ITIL IMPLEMENTATION CRITICAL SUCCESS FACTORS

\begin{tabular}{|c|c|}
\hline Research Studies & Findings \\
\hline $\begin{array}{l}\text { Office of Government Commerce } \\
\text { (2011) }\end{array}$ & $\begin{array}{l}\text { Requests must be fulfilled in an efficient and timely manner aligning with } \\
\text { the agreed service level targets for each type of request; only authorized } \\
\text { service requests should be fulfilled; and user satisfaction must be } \\
\text { maintained. }\end{array}$ \\
\hline Iden and Langeland (2010) & $\begin{array}{l}\text { Managers' ownership of ITIL introduction; senior management support of } \\
\text { ITIL; involvement of key personnel in designing and improving } \\
\text { processes; knowledge and understanding of process orientation; starting } \\
\text { with the ITIL processes having the greatest opportunities for success; } \\
\text { open and direct communication with personnel and customers about ITIL; } \\
\text { competence in ITIL processes; having a modular ITSM system for all } \\
\text { processes; demonstration of positive project results; training of ITIL } \\
\text { processes; having a standard system for measuring and reporting on } \\
\text { service levels; and be cognizant of the cultural impact due to ITIL } \\
\text { introduction. }\end{array}$ \\
\hline
\end{tabular}

Coelho and da Cunha (2009)

Resolving incidents quickly; maintaining service quality; managing quantity and quality of IT services; delivering services at affordable costs

Porter and Cater-Steel (2009)

Senior management support; training and staff awareness; virtual project team; careful software selection; use of consultants; interdepartmental communication and collaboration; process priority; ITIL-friendly culture; and customer-focused metrics

Cater-Steel and McBride (2007)

Senior management support; a communication strategy to dissipate messages and updates to employees throughout project implementation about the goals, objectives, roadmaps, and milestones achieved; ITIL foundation training for all senior managers and executives; and reinforce messages and updates by hosting regular brown bag lunch sessions and presentations during departmental meetings, posting signs and symbols at various locations within the physical environment, and displaying real-time service metrics, balanced scorecards, and outage figures easily visible to all employees.

Hochstein, Tamm, and Brenner

Senior management support; continuous service improvement (2005)

efforts; training and personnel development programs; and integration of new processes with existing operational activities. 
TABLE 5

METRICS, MEASUREMENTS, AND KEY PERFORMANCE INDICATORS

\begin{tabular}{|c|c|}
\hline Research Studies & Findings \\
\hline Steinberg (2013) & $\begin{array}{l}\text { Number of service requests fulfilled without service desk escalation; } \\
\text { number of service requests fulfilled without human intervention; number } \\
\text { of service requests fulfilled with proper authorization; number of service } \\
\text { requests that caused incidents; total available labor hours to work on } \\
\text { service requests; total labor hours spent fulfilling service requests; request } \\
\text { fulfillment tooling support level; and request fulfillment process maturity. }\end{array}$ \\
\hline \multirow[t]{4}{*}{ Talla and Valverde (2013) } & $\begin{array}{l}\text { Service Desk: Time to log the incident; time to acknowledge the user, } \\
\text { categorize and prioritize the incident, start the resolving action, and } \\
\text { complete the action; number of medium- and high-priority incidents. }\end{array}$ \\
\hline & $\begin{array}{l}\text { Incident Management: Number of incidents in open and closed state; } \\
\text { Number of incidents created and solved within the month. }\end{array}$ \\
\hline & $\begin{array}{l}\text { Problem Management: Number of incidents and problems; Average } \\
\text { number of incidents related to a problem. }\end{array}$ \\
\hline & $\begin{array}{l}\text { Change Management: Number of failed and emergency changes } \\
\text { implemented; Number of occurrences of process being circumvented, and } \\
\text { percentages of these numbers; Number of occurrences when the critical } \\
\text { level is reached, escalation is performed, and percentages of these } \\
\text { numbers. }\end{array}$ \\
\hline $\begin{array}{l}\text { Office of Government Commerce } \\
\text { (2007) }\end{array}$ & $\begin{array}{l}\text { Total number of service requests; number of service requests at each stage } \\
\text { of the request fulfillment process; number of current backlog of } \\
\text { outstanding service requests; mean elapsed time for handling each type of } \\
\text { service request; number and percentage of service requests completed } \\
\text { with service level agreement; average cost per service request type; and } \\
\text { level of customer satisfaction with handling of service requests. }\end{array}$ \\
\hline Gacenga et al. (2011) & $\begin{array}{l}\text { Number of incidents, problems, and service requests created and resolved; } \\
\text { trend analysis; number of known errors; number of failed changes } \\
\text { (incidents arising from changes); mean time to restore services; first call } \\
\text { resolution percentage; timeliness of resolution (adherence to target } \\
\text { resolution timeframes); number of misclassification of incidents and } \\
\text { number of process avoidance by work unit; service level compliance; } \\
\text { mean time between failures; overall availability of services; number of } \\
\text { service requests by service, by location, by user; and number of incidents } \\
\text { by service, by priority, and by location. }\end{array}$ \\
\hline
\end{tabular}

\section{METHOD}

This research utilized components of the qualitative research approach, descriptive research strategy, and case study research tradition (strategy of inquiry). To select participants, the researcher determined that purposeful sampling would be the most direct and meaningful approach to maximize discovery (Groenewald, 2004; Kelly, 2010). The participants selected for this study were employees of an IT service provider group working for a large university in the Northeast region of United States. They were working as full-time employees for at least one year and used the request fulfillment process on a daily 
basis. Based on these three selection criteria (type of employment, length of employment, and frequency of using the request fulfillment process), eight of 13 group members were selected: a director, an associate director, a manager, a senior data analyst, a data analyst, two consultants, and a business analyst. The demographics of these participants were as follows: five females, three males, six Caucasian, and two Asian employees. The ages of the participants ranged from late 20 s to 65 years.

\section{Data Collection}

The study followed a qualitative research tradition in which data (information) came from interviews with the participants, their stories, testimonials, and physical artifacts created and used by them (Yin, 2014). As stated earlier, there were eight participants of a small IT group - large enough to complete the interviews in a time frame given the time restrictions for each interview, yet small enough to dive deep into the research question (Creswell, 2009; Krathwohl \& Smith, 2005). The interviews were face-to-face and took place between May 1 and May 31, 2016. The interviews were open-ended and conversational, and lasted between 45 to 60 minutes each. The interviews were audio-recorded and transcribed. The interview transcripts included both the actual words spoken by the participants and any observations of non-verbal communications that could enable building on the meaning of the statements (Hycner, 1985). Complete written interview transcripts were provided to the participants so they could clarify and verify all data. Participants returned the transcripts to the researcher with additional thoughts and clarifications on the ideas raised during interviews. All participants were assured of their anonymity and any personal identifying data were double-checked to ensure their removal.

Yin (2014) stated that archival records contain evidence of past activities-examples include public use files, service records, organizational records, maps and charts, or survey data. For this study, JIRA was the archival records source which stored all service requests placed upon the group by its users and customers since July 2014 when the request fulfillment process officially went into effect. As of October 18,2015 , over 4,600 service requests were placed, and the number was expected to grow every day due to continuous business operations and services provided by the group. JIRA stored detailed information on every single service request in the form of database records. A physical artifact is "a technological device, a tool or instrument, a work of art, or some other physical evidence" that can be collected and evaluated as a part of case study (Yin, 2014, p. 117). For this study, the following resources, documents, and physical artifacts were collected and evaluated:

- Reports and files produced by the group in completing a service request. Examples are Enrollment reports, Demographic reports, Application reports, etc.

- Various training materials created and regularly maintained and used by the group members.

- The Onboarding documentation and checklists followed when a new employee came onboard.

- The request fulfillment process document that outlined the process steps and provided detail description of each step.

- Notes and minutes from weekly team meetings.

All documents were stored electronically in a network drive accessible only by the staff members of the group. The collection of data from different sources was reviewed and analyzed together, so the study findings could be based on the convergence of information from different sources. The use of multiple sources for data collection also facilitated data triangulation.

\section{Data Analysis}

Data collected in this study comprised large quantities of texts, notes, reports, and audio files. All collected data were systematically dissected, rearranged, organized, and interpreted by the researcher to answer the research question and present research findings (Evers \& van Staa, 2010). Data analysis was carried out using data triangulation and continuous coding process. Data triangulation was performed based on three sources - interviews, archival records, and physical artifacts. For each data source, continuous coding process began with open coding, when the raw data (interview transcripts, field notes, 
etc.) were examined word by word, line by line, and incident by incident to define actions or events within data (Charmaz, 2006). The analysis of axial coding was performed next as the researcher developed and related categories. Then, categories were further defined by selective coding, "an integrative process of selecting the core category, systematically relating it to other categories, validating those relationships by searching for confirming and disconfirming examples, and filling in categories that needed further refinement and development" (Creswell, 2009, p. 160; Strauss \& Corbin, 1998). Codes and categories were sorted, compared, and contrasted until saturation was reached-when all data were accounted for in the core categories, and no new codes or categories could be produced (Creswell, 2009).

Guest, Bunce, and Johnson (2006) mentioned that saturation of basic themes can be achieved in six interviews. Therefore, the present study achieved basic data saturation by interviewing eight participants. Verification of coding was also performed by a second coder. The researcher and the second coder independently reviewed the codes, the meaning and context behind the coding, and verified the codes for convergence of themes in relation to the existing literature, research, and practices in the IT and ITSM fields. The categorizations of themes agreed by both the researcher and the second coder were taken into consideration as valid themes and are discussed in the following section.

\section{RESEARCH FINDINGS}

\section{Theme 1: Trend Analysis}

Three primary reasons became evident for this perception of trend analysis as important: to identify areas where the process is performing well so that the group can duplicate success; to identify areas where the process is underperforming; and to provide evidence of making decisions based on data rather than a hunch or a best guess. Trend analysis was important for the group because it is the practice of collecting and comparing past and present information to identify a pattern or trend, predict future events or scenarios, and make informed decisions. One of the participants attributed trend analysis to value drivers such as decreased service downtime, increased customer satisfaction, confidence in offered services, and superior help desk performance. According to the group's manager, trend analysis helped the group understand how the request fulfillment process performed in the past and predict where the current operations and practices of the process may take them next. He felt very strongly about capturing and displaying trend numbers on the dashboards, and once mentioned trend analysis as a cornerstone of being proactive in managing service requests and incidents.

Although trend analysis can be performed on any data that the group captured over time, the group identified four metrics for which trend analysis was deemed useful: total number of tickets (all priority levels) created per month, total number of tickets (all priority levels) closed per month, number of Priority-1 (P-1) tickets created per month, and number of P-1 tickets closed per month. The group decided that these four metrics should be displayed in two separate graphs - the first graph showing total number of tickets created and closed per month in a stacked-column bar chart format; and the second graph showing number of only P-1 tickets created and closed per month-also in a stacked-column bar chart format (See Figure 1). Tickets with other priorities (e.g. P-2, P-3, P-4, and P-5) were documented in other reports and were not displayed in the dashboard. 


\section{FIGURE 1 \\ TREND ANALYSIS DASHBOARD PAGE}
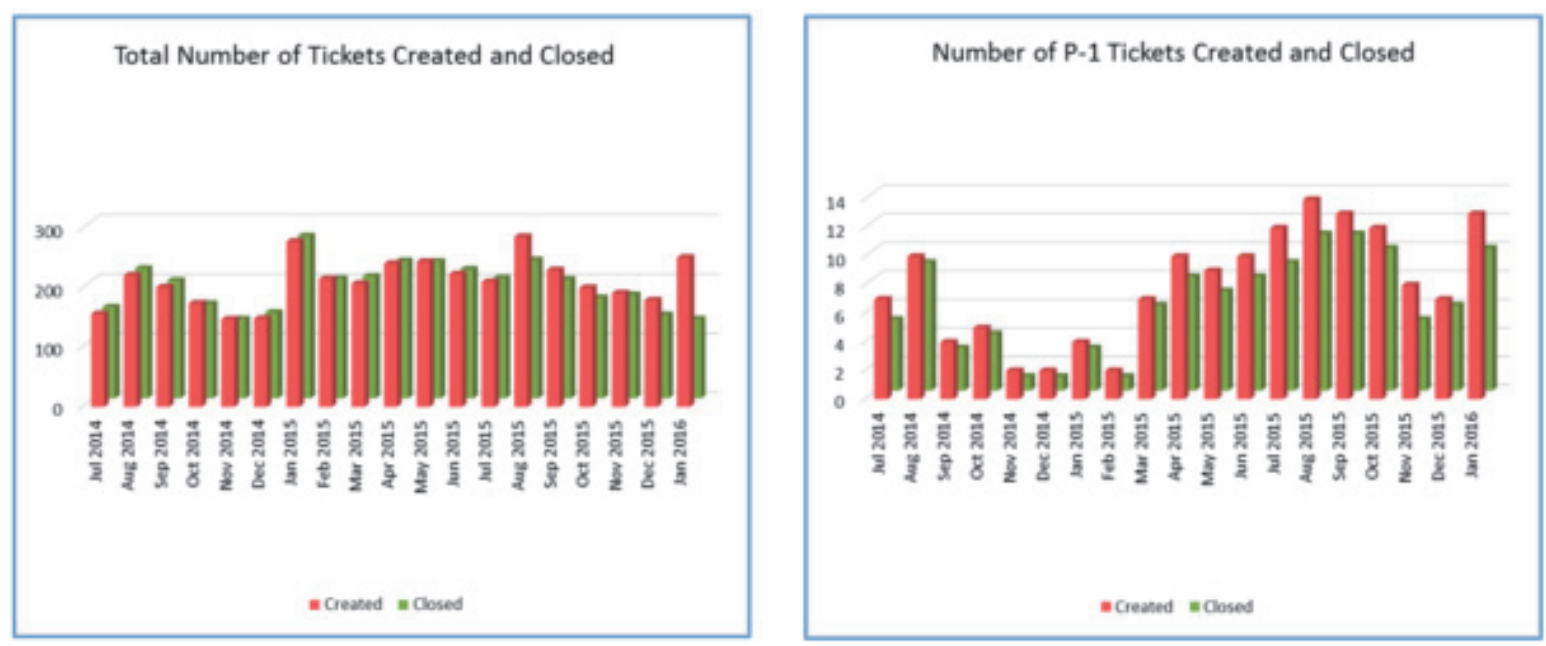

\section{Theme 2: Monthly Operational Summary}

All participants in this research study expressed a need to see various summary numbers for monthly operations on the dashboard. Making operational data available to all group members, stakeholders, and customers of the group was viewed as a powerful tool for mapping performance against corporate goals and key performance indicators that have been agreed by management and communicated to all group members. The group operated like a service desk designed to serve as a single point of contact for all data and reporting requests and was responsible for handling recurring and ad hoc requests from the users. Showing monthly operational summary numbers on the dashboard was imperative for three major reasons: first, to turn raw data gathered from the request fulfillment process into information on which informed management decisions could be based; second, to strengthen the case for obtaining additional resources and funding for the group by communicating the value provided by the group; and third, by demonstrating the group as high-potential and capable of providing services in terms of quality and timeliness.

The group's director was interested in operational numbers to assist her in the decision making process and believed that by using the operational summary numbers of the request fulfillment process, her team would be able to make informed, rational decisions about the data, reports, and other services offered to her users. Another participant expressed similar sentiments as she referred to operational numbers as an indicator of the group's service level and performance. The manager of the group felt that operational numbers could be used when sending the request for additional funding and resources to the Executive Director. As the entire organization had recently faced a budget cut, obtaining additional funding for new positions proved to be a real challenge and had to be based on operational numbers that show more money or more people are needed to get the job done correctly and on time.

The following four metrics were identified as the monthly operational summary to be displayed on the dashboard: number of tickets by issue type, number of tickets by priority, number of tickets by issue status, and number of tickets by department/area. In response to how the group wanted to see these numbers displayed on the dashboard, the group agreed that a pie chart would be appropriate to display each metric in the dashboard (See Figure 2). 
FIGURE 2

MONTHLY OPERATIONAL SUMMARY DASHBOARD PAGE
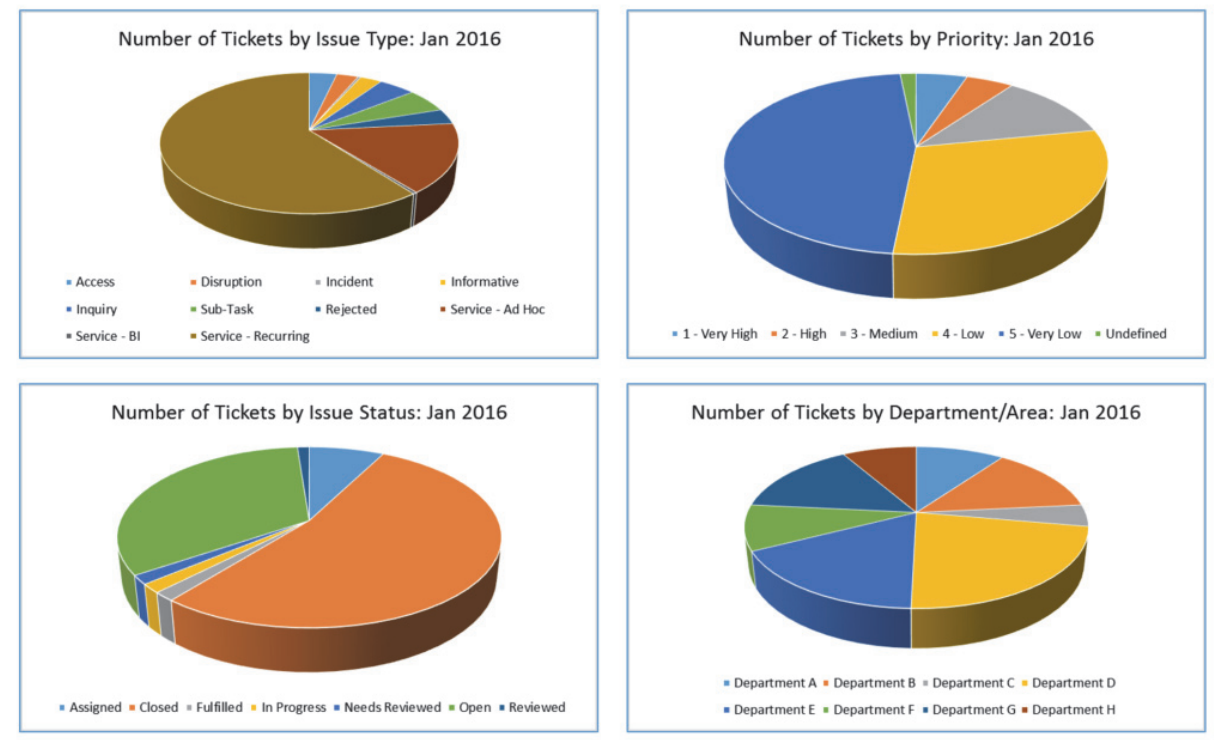

\section{Theme 3: Monthly Workload Distribution Summary}

The director of the service provider group in this study wanted to transform it into a high-performing team in which employees were asked to contribute at their highest potential and learn along the way while having fun and enjoying the workload in a collaborative environment. She firmly believed that employees' job satisfaction levels in a constantly changing, highly demanding, and stressful IT support team like hers were likely to increase when employees found that the workload was being assigned, distributed, and delegated in a fair, balanced, and transparent manner. Group members believed strongly that service requests should be assigned to them fairly, everyone should be fully aware of who was working on what, and the number of service requests assigned to each member.

Fair and balanced distribution of the workload was attributed to much positive feedback from group members. Since the group members knew the workload would be assigned fairly, they had solid and deep trust in each other and in the team's purpose. They felt free to express feelings and ideas. The newest team member expressed her amazement at the teamwork and looked very cheerful when she mentioned that everybody in the team believed they were working toward the same goals and accomplishing tasks. Another member was also very pleased at how well the staff members got along with each other. He delightfully stated that the group understood both team and individual performance goals and knew what is expected. They also actively diffused tension and friction in a relaxed and informal atmosphere. But no team is immune from conflict or differences in opinion. To resolve conflicts, the team engaged in extensive discussion during team meetings, and all team members got a chance to contribute and showcase their weekly accomplishments - no matter how small or insignificant they might sound. Disagreement was expressed with courtesy. Criticism was constructive and oriented toward problem solving and removing obstacles.

Since fair and balanced workload distribution was viewed as a critical factor in becoming highperforming and successful team, staff members wanted to see six metrics on the dashboard on a monthly basis for the executive leaders of the department and the organization. These six metrics were: number of tickets per assignee, number of tickets per reviewer, number of tickets per assignee and priority, number of tickets per assignee and issue type, number of tickets per assignee and issue status, and number of tickets per department/area and issue type. The first two metrics were presented as horizontal bar charts whereas the rest of the metrics were presented as two-dimensional tables (See Figure 3). 
FIGURE 3

MONTHLY WORKLOAD DISTRIBUTION SUMMARY DASHBOARD PAGE

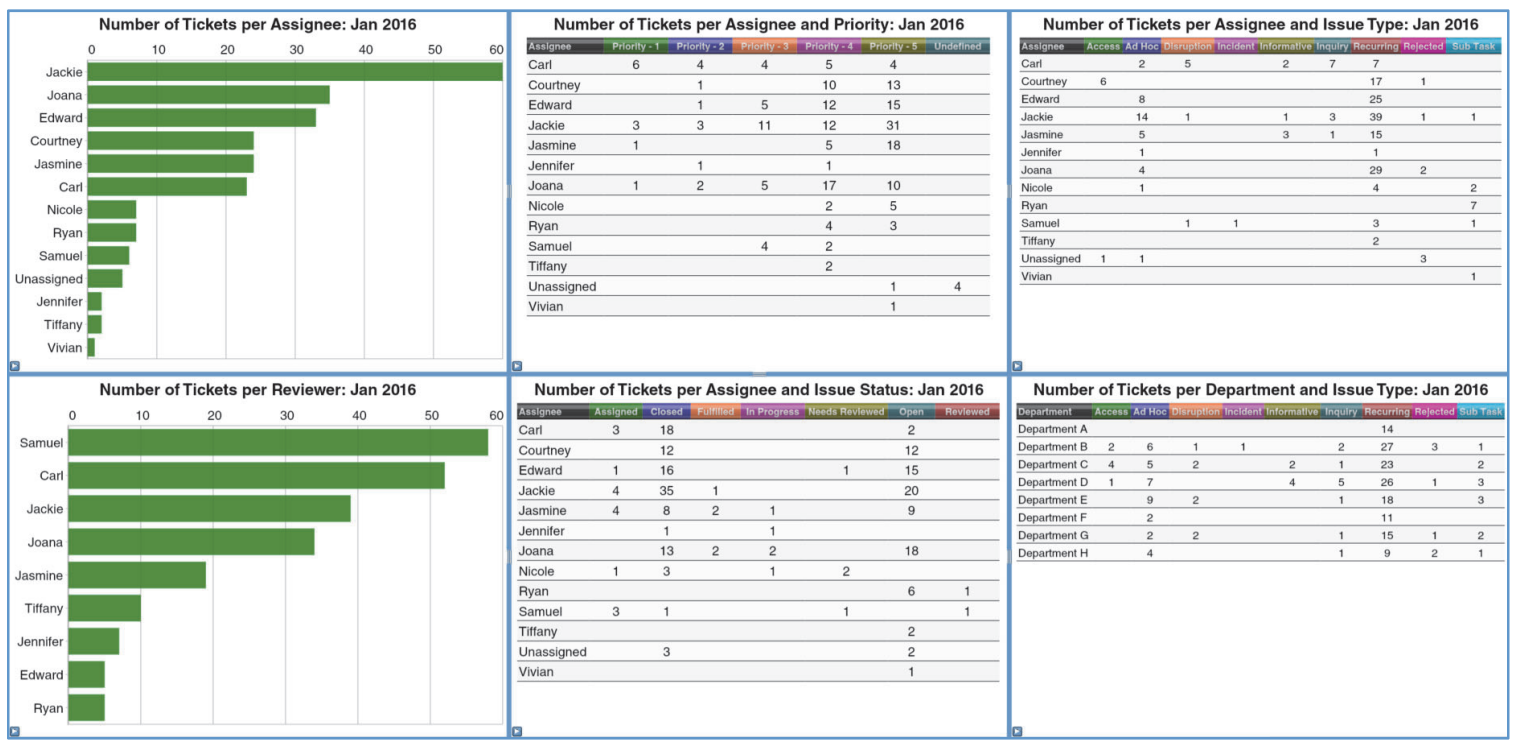

\section{DISCUSSION}

\section{Metrics from Service Providers' Perspective-Demonstrating Value}

This research study suggested that there is limited but fast-growing acceptance and adoption of metrics in the IT Service Management industry, and more businesses and IT leaders are depending on verifiable quantitative information to make strategic and operational decisions. Although many service desks and IT service providers have adopted various metrics, there is no definite set of most important metrics due to a wide range of opinions. The participants in this study mentioned many metrics that they felt were important, but it was not a reasonable expectation to include them all in the dashboards. Ultimately, only a limited number of metrics were selected to be most important and worthy of presenting in the dashboards, and the team leaders (director, associate director, and manager) had the final say. The offering of a wide range of opinions from participants can be explained in a nutshell: every service provider group is different, operates under a different corporate culture, provides different types of services, and seeks a wide range of data, information, and evidence to make important decisions on resource allocation, service delivery, customer satisfaction, etc.

All participants in this study had at least five years of IT experience working full-time in various organizations and industries, and they shared insights related to metrics and measurements not only based on their current positions, but also based on their past experiences. They mentioned almost two dozen performance metrics that they had measured in the past. The two most frequently used performance metrics stated by participants included number of incidents and service requests and percentage of incidents and service requests resolved within due dates (also known as the Service Level Agreement or SLA). It is noteworthy that several of these metrics were also deemed important by the whole team during the focus group session, some metrics were considered appropriate for future development, while few were regarded totally irrelevant or not applicable based on current business practices of the group.

Number of incidents and service requests was expected to be universal—without it, service provider groups would not be able to deploy resources appropriately and ensure they are operating at full capacity. Simply stated, this metric signifies the work a service provider group does on a daily, weekly, or monthly basis. By doing a trend analysis over a certain period, this metric reveals whether a service provider is becoming busier or not, and if more or fewer resources are needed to operate at an optimal level in responding to customer requests in a timely manner. The percentage of incidents and service requests 
resolved within due dates or SLA measures how well service providers are adhering to the contracts that exist between them and their stakeholders. However, many organizations do not have well-established contracts or SLAs between service providers and the stakeholders they support. When there is a lack of well-defined SLAs, due dates - often determined arbitrarily-can be taken into consideration to determine service providers' level of adherence. For many service providers, SLAs and level of customer satisfaction are the key performance indicators (Wood, 2013).

To demonstrate value, the metrics that are important and relevant need to be identified, and the responsible parties for producing, measuring, and reporting those metrics must also be functioning properly. For service providers, the managers are usually accountable for these tasks because they generally have the overall control, visibility, and responsibility for the operation of the group. However, participants in this study shared that they often depend on input from other members within the team, and sometimes on members from other functional areas to obtain and verify accurate numbers before publishing a metric. It was clear from the interviews that despite occasional overlap, each group member had different areas of responsibilities, and it was too time-consuming for one person to capture and analyze all data before measuring and presenting a metric. To overcome this challenge, the participants found the RACI matrix very helpful. RACI is a responsibility assignment matrix that examines a process step, task, activity, or effort to determine who is Responsible (the person who is assigned to do the work), Accountable (the person who makes the final decision and has the ultimate ownership), Consulted, (those who must be consulted before completing the task), or Informed (those who must be informed when the task is complete).

Metrics must be published or reported on a regular basis by service providers. Depending on the business needs and capabilities of the provider, metrics can be reported in real-time, daily, weekly, monthly, quarterly, semi-annually, annually, or an ad-hoc basis. The participants in this study understood that there are different audiences for different metrics due to the variation, range, and sensitivity of information they contain. Therefore, not all metrics should be published or reported to all stakeholders. Weekly metrics were primarily reviewed by staff members to highlight the week's performance against targets, while monthly metrics usually started at a higher level and could be drilled down to more details. The participants also believed that creating different dashboards or views of the metrics containing appropriate information for different stakeholder was a powerful and effective way to demonstrate the value and usefulness of metrics. Metrics must also be presented to the right parties and stakeholders to demonstrate their value. Typically, these stakeholders were the members of the service provider group, senior executives (Executive Director, Vice President, and CIO), internal and external customers, and vendors. Several participants mentioned the importance of the level of stakeholders' interest in the metrics presented to them. Different stakeholders may display varying degrees of interest, but service providers should take this as an opportunity to conduct additional needs analysis with the stakeholders who exhibit a low level of interest and understand what the stakeholders truly need and how they want the information to be presented. Fully automated real-time dashboards may sound tempting but unnecessary to some stakeholders. Service providers should also know whether the customers, end users, and stakeholders are making decisions based on the metrics provided to them, or at least helping them to improve the decision-making process. The value of most accurate, real-time dashboards would be nonexistent if not used to make or facilitate critical operational or strategic business decisions.

\section{Metrics from the Business Perspective}

In this section, research findings are discussed from the business perspective. Metrics that are deemed most important by the business and commonly include profitability, growth, and cost-based metrics. As stated in a previous section, the participants in this research study had at least five years of industry experience in IT Service Management in various organizations in the U.S. Based on the participants' experiences, businesses are primarily interested in the performance of the service providers and customer satisfaction numbers are considered de facto in measuring performance. It was obvious that businesses care about what customers think of the services they receive from the service providers. The research participants observed a relationship between an increased number of unresolved tickets and lower 
customer satisfaction numbers. Although there is no empirical evidence for this relationship, hearing similar observations from multiple participants was certainly thought-provoking.

Identifying one metric that is most important to the business is not easy, and often not possible. However, customer satisfaction, number of incidents and requests resolved within the SLA, availability of services, and cost of operations were frequently mentioned by the participants in this study. This suggests that the most important metrics perceived by the business are common among various service provider groups. Other metrics deemed most important by the business included cost-based metrics (e.g., cost of ownership, cost of operations, cost per incident or service request), average time to resolve incidents and service requests, average time to respond, first time resolution rate, number of backlog tickets, etc. While it is common for the business to have different expectations of what should be measured compared to what service providers actually measure, metrics such as customer satisfaction and meeting the SLA are perceived as being critical by both the business and the service providers as key measures of their performance (Wood, 2013).

In addition to demonstrating how well the service provider group is currently operating by identifying performance metrics (e.g., trend analysis, operational numbers, workload distribution numbers), the emphasis placed by participants on several business value metrics cannot be ignored. As the name suggests, business value metrics are measures considered beneficial to the business. These metrics provide a clear idea of performance and value to the business. One example of business value metrics mentioned by participants was the number of lost IT service and business hours, also known as downtime. The cost of data center downtime has increased significantly in recent years. According to the study of U.S. data centers, the average cost of an unplanned data center outage is more than $\$ 7,900$ per minute (Sverdlik, 2013). Knowing the number of lost IT service hours indicates how long IT services were unavailable to the business and customers and promotes discussion surrounding why hours were lost, how much did the downtime cost the business, and what actions can be taken to proactively prevent downtimes in the future. The number of lost business hours signifies IT's importance to the organization and should be carefully reviewed to ascertain exactly how much revenue was lost due to services being down (Wood, 2013). The participants in this research study understood the importance of these business value metrics, and overwhelmingly wanted to measure and report these metrics in future when additional resources and capabilities are available.

\section{IMPLICATIONS}

The results of this study are important to persons interested in identifying metrics and creating dashboards. Moreover, the results have important implications for practitioners and researchers. This study puts forward the necessity of perceiving the quality of IT services from four different perspectives (customer, operational, capability, and financial service metrics) and critical success factors. Studies on customer service metrics can aid IT service providers measure customers' perception of the services and answer research questions on customer satisfaction (how well the service meets customer expectations), customer loyalty (how well and often customers return to use the service), and market share (how much of the market is being served by the service). Research on operational service metrics will allow IT service providers to measure the efficiencies and effectiveness of operational activities and resources utilized to deliver services. Studies on operational service metrics can be carried out to determine service availability (percent of time the service is available), service accuracy (percent of time the service produces accurate results), service performance (response time of the service meeting targets), supplier performance (how well the suppliers deliver services), support turnover (turnover rate of support staff), service compliance (how well the service complies with rules and regulations), and service flexibility (how quickly the service responds to changing business requirements).

Future research projects should also study capability and financial service metrics. Understanding capability service metrics can support IT service providers by measuring, managing, and improving the capabilities, skills, capacities, and performance of the services being offered. These studies may include topics such as service capacity (ability to meet current and future customer demands), service 
recoverability (ability to recover the service from a disruption), support skills (capability and skills of staff members supporting the service), technology performance (technology capability to support the service), and supportability (capability to support the service). Finally, future studies focusing on financial service metrics can help IT service providers identify the cost and revenue performance of the services provided. These studies can answer research questions pertaining to cost performance (how costcompetitive the service is compared to other similar services in the marketplace), revenue performance (how much the service is aligned to business revenue goals), and budget performance (how well the service adheres to planned costs and expenditures).

IT Service Management practitioners unable to implement a robust metrics program in their organization or department due to various challenges and resource constraints should still try to establish a minimal metrics program (Steinberg, 2013) when relevant data to calculate metrics are difficult to obtain. Typical challenges faced by this study's participants included disparate data collection and reporting tools, difficulty in aggregating and summarizing data, lack of a "golden" source of data - the source with unequivocal data, and a lack of automation in collecting and reporting the data. Rather than abandoning the metrics program, this case study illustrates that establishing a minimal metrics program based on indicators, random inspection results, analogous measures, and audit results can be valuable. Indicators "are based on some observable operational event for which an operating quality assumption is derived" (Steinberg, 2013, p. 136). Random inspection results "represent observable events for which an assumption is made that they apply to all similar events" (p. 137). Analogous measures are "observable metrics from which assumptions will be derived that other events have occurred" (p. 138). Audit results consist of measures from "periodic audit activities that are conducted for specific operational events" (p. 140). Using a minimal metrics program based on these techniques is especially helpful for IT service providers where programmed metrics are very difficult to obtain without undertaking a long-term major project. This study makes similar observations to Steinberg (2013) that IT service providers can establish a minimal metrics program based on constant management communications, clear understanding among all stakeholders, and agreement to techniques employed.

Research and case studies with real-life examples of how to initiate, design, build, test, and implement ITIL metrics programs of different sizes and complexities can be highly valuable and useful to IT Service Management practitioners. Examples of research topics for the program initiation step can include program scope, charter, and work plan. For the program design step, roles and responsibilities, skills and training requirements, stakeholder analysis, and tools and processes to collect, report, and review data needed to create the metrics should be studied. Examples of training materials, test scripts, and test results can be valuable in building and testing a metrics program. Future research should also study successful metrics program implementations and identify lessons learned while validating program goals, finding areas of continuous service improvement, managing diverse stakeholders, and rolling out the program.

\section{CONCLUSION}

In this study, the researcher examined the request fulfillment process of an information technology service provider group members to gain their perceptions of the most important metrics of the process, and subsequently created dashboards to display those metrics. Analysis of data led to the identification of a variety of enablers and constraints that converged across three themes: trend analysis, monthly operational summary, and monthly workload distribution summary. Each of these themes (dashboard pages) and their associated categories (metrics) are important areas of future research that may offer results needed to understand the real drivers behind the perceived need for a metric. In addition, research may be expanded to include other IT Service Management processes (e.g. Incident Management, Problem Management, Change Management, etc.) in different organizations and service providers with varying user populations.

IT Service Management programs should be studied in organizations with varying budgetary requirements and in various implementation stages of the program lifecycle. In this study, only full-time 
employees of a small IT service provider group were selected for participation. Future studies should also take into consideration the input of part-time employees - those who use IT Service Management processes on a regular basis as a job requirement, and consultants - those who typically have many years of experience in diverse industries. Their input may provide additional insights into IT Service Management processes resulting in additional metrics.

This paper used a qualitative case study approach to answer the research questions. Future research studies should examine whether other qualitative research methods - such as narrative inquiry, ethnography, or phenomenological study - are more appropriate and suitable for this purpose. These research methods can address various topics such as participants' experiences of ITIL adoption, customer care, or process improvement; understanding different perspectives of participant groups, such as service providers, customers and end users, stakeholders, and senior managers; and how experiences, attitudes, and life circumstances affect the needs and behaviors of different participant groups. Finally, this research study was limited to identifying important metrics perceived by only the group members and did not account for different stakeholders' perspectives, which may be another area to consider in future research.

\section{REFERENCES}

Anderson, B. (2009). ITIL background and history. Retrieved from: http://www.itservicemanagementitil.com/uncategorized/itil-background-history/

Axelos. (2019). ITIL Update. Retrieved from https://www.axelos.com/itil-update

Cater-Steel, A., \& McBride, N. (2007, June). IT service management improvement - actor network perspective. In Proceedings of the 15th European Conference on Information Systems (ECIS 2007) (pp. 1202-1213). University of St. Gallen.

Cater-Steel, A., Tan, W., \& Toleman, M. (2006, November). Challenge of adopting multiple process improvement frameworks. Paper presented at the European Conference on Information Systems (ECIS) - 2006. Retrieved from: http://aisel.aisnet.org/ecis2006/177

Charmaz, K. (2006). Constructing grounded theory: A practical guide through qualitative analysis. Thousand Oaks, CA: Sage Publications.

Coelho, A. M., \& da Cunha, P. R. (2009, August). IT service management diagnosis at Grefusa Group and ITIL implementation proposal. Paper presented at the Americas Conference on Information Systems (AMCIS) - 2009. Retrieved from: http://aisel.aisnet.org/amcis2009/519.

Creswell, J. W. (2009). Research design: Qualitative, quantitative, and mixed methods approaches. Thousand Oaks, CA: Sage.

Creswell, J. W. (2013). Qualitative inquiry \& research design. Choosing among five approaches (3rd ed.). Thousand Oaks, CA: Sage Publications.

Disterer, G. (2012, June). Why firms seek ISO 20000 certification: A study of ISO 20000 adoption. Paper presented at the European Conference on Information Systems (ECIS) - 2012. Retrieved from: http://aisel.aisnet.org/ecis2012/31

Espindola, R. S., Luciano, E. M., \& Audy, J. L. N. (2009, January). An overview of the adoption of IT governance models and software process quality instruments at Brazil - preliminary results of a survey. Paper presented at the 42nd Hawaii International Conference on System Sciences. Retrieved from: http://ieeexplore.ieee.org/xpl/articleDetails.jsp?arnumber $=4755737$

Gacenga, F., Cater-Steel, A., Tan, W., \& Toleman, M. (2011, December). IT service management: Towards a contingency theory of performance measurement. Paper presented at the $32^{\text {nd }}$ International Conference on Information System, Shanghai, 1-18. Retrieved from: http://aisel.aisnet.org/cgi/viewcontent.cgi?article=1189\&context=icis2011

Gacenga, F., Cater-Steel, A., \& Toleman, M. (2010). An international analysis of IT service management benefits and performance measurement. Journal of Global Information Technology Management, 13(4), 28-63. 
Gacenga, F., Cater-Steel, A., Toleman, M., \& Tan, W. G. (2011). Measuring the performance of service orientated IT management. Sprouts: Working Papers on Information Environments, Systems and Organizations, 11(162). Retrieved from: http://sprouts.aisnet.org/11-162

Groenewald, T. (2004). A phenomenological research design illustrated. International Journal of Qualitative Methods, 3(1). Article 4. Retrieved from: http://www.ualberta.ca/ iiqm/backissues/3_1/pdf/groenewald.pdf

Guest, G., Bunce, A., \& Johnson, L. (2006). How many interviews are enough? An experiment with data saturation and variability. Field Methods, 18(1), 59-82. doi:10.1177/1525822X05279903

Heller, M. (2013). Running IT like a business: Interview with Rob Webb, former CIO of Hilton Worldwide and CEO of the TBM Council. Retrieved from: http://www.cio.com/article/2370229/cio-role/running-it-like-a-business/cio-role/cio-role/runningit-like-a-business.html

Hochstein, A., Tamm, G., \& Brenner, W. (2005, May). Service-oriented IT management: Benefit, cost and success factors. Paper presented at the European Conference on Information Systems (ECIS) 2005 Proceedings. Retrieved from: http://aisel.aisnet.org/ecis2005/98/

Hoerbst, A., Hackl, W. O., Blomer, R., \& Ammenwerth, E. (2011). The status of IT service management

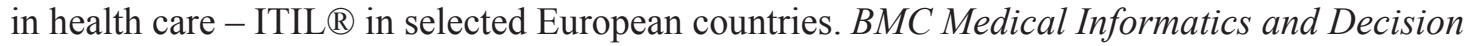
Making, 11(76), 2-12.

Hycner, R.H. (1985). Some guidelines for the phenomenological analysis of interview data. Human Studies, 8, 279-303.

Iden, J, \& Eikebrokk, T. R. (2013). Implementing IT service management: A systematic literature review. International Journal of Information Management, 33, 512-523.

ITILNews. (2016). ITIL v3: What are the ITIL core books or publications. Retrieved from: http://www.itilnews.com/index.php?pagename=ITIL_v3_What_are_the_ITIL_ Core Books or Publications

Jira. (2015). In Wikipedia. Retrieved on October 14, 2015 from: https://en.wikipedia.org/wiki/JIRA

Kelly, M. C. (2010). A case study in citizen leadership during crisis: The experiences of the women of the storm (Unpublished doctoral dissertation). The Pennsylvania State University, PA.

Krathwohl, D. R., \& Smith, N. L. (2005). How to prepare a dissertation proposal: Suggestions for students in education and the social and behavioral sciences. Syracuse, NY: Syracuse University Press.

Kumbakara, N. (2008). Managed IT services: The role of IT standards. Information Management \& Computer Security, 16(4), 336-359. doi:10.1108/09685220810908778

Lapão, L. V. (2011). Organizational challenges and barriers to implementing IT governance in a hospital. Electronic Journal of Information Systems Evaluation, 14(1), 37-45.

Mann, S. (2011). IT service management metrics: Advice and 10 top tips. Retrieved from: http://blogs.forrester.com/stephen_mann/11-10-14it_service_management_metrics_advice_and_10_top_tips

Marrone, M., \& Kolbe, L. M. (2011). Impact of IT service management frameworks on the IT organization. Business \& Information Systems Engineering, 3(1), 5-18. doi:10.1007/s12599-0100141-5

Marrone, M., \& Kolbe, L. M. (2011a). Uncovering ITIL claims: IT executives' perception on benefits and business-IT alignment. Information Systems and e-Business Management, 9(3), 363-380. doi:10.1007/s10257-010-0131-7

Mendes, M., \& Mira da Silva, M. (2011). Implementing a request fulfillment process. In M. Snene, J. Ralyte, \& J-H. Morin (Eds.), Exploring Services Science (pp. 113-126). Berlin: Springer Berlin.

Office of Government Commerce. (2007). Service operation. London: TSO.

Office of Government Commerce. (2011). Service operation. London: TSO.

Office of Government Commerce. (2011a). ITIL continual service improvement. London: TSO.

Overby, S. (2004, May). How to run I.T. like a business. CIO, 48-56. 
Pollard, C., \& Cater-Steel, A. (2009). Justifications, strategies, and critical success factors in successful ITIL implementations in U.S. and Australian companies: An exploratory study. Information Systems Management, 26(2), 164-175. doi:10.1080/10580530902797540

Spafford, G. (2009). What are metrics? Retrieved from: http://www.processdox.com/Documents/3852_metrics_revised_12-07-09.pdf

Steinberg, R. (2013). Measuring ITSM: Measuring, reporting, and modeling the IT service management metrics that matter most to IT senior executives. Bloomington, IN: Trafford Publishing.

Strauss, A., \& Corbin, J. (1998). Basics of qualitative research: Techniques and procedures for developing grounded theory. Thousand Oaks, CA: Sage.

Sverdlik, Y. (2013). One minute of data center downtime costs US \$7,900 on average. Retrieved from: http://www.datacenterdynamics.com/content-tracks/power-cooling/one-minute-of-data-centerdowntime-costs-us7900-on-average/83956.fullarticle

Talla, M., \& Valverde, R. (2013). An implementation of ITIL guidelines for IT support process in a service organization. International Journal of Information and Electronics Engineering, 3(3), 334-340. doi:10.7763/IJIEE.2013.V3.329

Tan, W., Cater-Steel, A., \& Toleman, M. (2009). Implementing IT service management: A case study focusing on critical success factors. The Journal of Computer Information Systems, 50(2), 1-12.

Tan, W., Cater-Steel, A., Toleman, M., \& Seaniger, R. (2007, December). Implementing centralised IT service management: Drawing lessons from the public Sector. Paper presented at the Australasian Conference on Information Systems, Toowoomba. Retrieved from: http://www.researchgate.net/publication/228653786

Wan, S. H. C., \& Chan, Y. (2008). Improving service management in campus IT operations. CampusWide Information Systems, 25(1), 30-49. doi:10.1108/10650740810849070

Winniford, M., Conger, S., \& Erickson-Harris, L. (2009). Confusion in the ranks: IT service management practice and terminology. Information Systems Management, 26(2), 153-163. doi:10.1080/10580530902797532

Wood, D. (2013). Demonstrating service desk value through more meaningful metrics. Retrieved from: http://www.servicedesk360.com/wp-content/uploads/2013/05/Meaningful_Metrics_online.pdf

Yin, R. (2014). Case study research: Design and method (5th ed.). Thousand Oaks, CA: Sage. 